\title{
BANKRUPTCY DETERMINANTS IN TIME VARIANT SETTINGS
}

\author{
Elena Lancosova ${ }^{1}$
}

DOI: https://doi.org/10.31410/ITEMA.S.P.2019.53

\begin{abstract}
This paper aims to assess importance of widely used bankruptcy discriminants in dynamic, time dependent environment as opposed to more traditional, static methods used in bankruptcy models. Such setting gives way to new, process oriented, point of view on companies nearing their bankrupt. Subsequently, new simple discriminants with stronger relationship to bankruptcy are proposed while strictly using only widely available information from accounting statements. Behaviour of both proposed and traditional discriminants is examined through kernel smoothing and discriminant's evolution before bankruptcy and thus the reasons behind their respective predictive powers are uncovered.
\end{abstract}

Keywords: Survival Analysis, Time Dependent, Dynamic, Assets, Equity, Sales, Change from Previous Period, Kernel Smoothing, Accounting Statement.

\section{INTRODUCTION}

$\mathrm{T}$ he ability to correctly predict company's future development is very desired among every investor, manager, owner or creditor. To this end, knowledge of the process of bankruptcy and its determinants is of the utmost importance.

There are two main approaches to company's financial situation assessment, horizontal analysis with its focus on changes in time and vertical analysis using ratio indicators. Since each such indicator offers limited information on its own due to its focus on single aspect of overall financial and economic situation, complex systems of these indicators, so called bankruptcy models, were created. Should we wider our focus even more and incorporate time into our estimate, we would gain additional dimension to insolvency risk estimation, time, and effectively connect vertical and horizontal financial analysis.

In the past, discriminant analysis and logistic regression were used for bankruptcy model creation, but development of computer technology and company databases have allowed for inclusion of different methods, some of them with potential of incorporating time into insolvency risk assessment, such as survival analysis.

Survival analysis comprises several statistical methods exploring time until event, event being for example credit default or company bankruptcy as in our case. It perceives bankruptcy as a process happening in time. Thus, its prime aim is not to estimate bankruptcy risk but rather to estimate time left until bankruptcy inevitably happens. This point of view is, in our opinion, closer to economic reality and can provide us with richer information regarding bankruptcy as a process.

Ratios like return on assets are widely used with methods without time dimension but would they be just as influential when dynamic method is used? If not, then where should an analyst really look when assessing company's health? This paper aims to answer these questions by survival model estimation and significance of individual bankruptcy determinants assessment.

Masaryk Univesity, Faculty of Economics and Administration, Lipová 41a, 60200 Brno-střed, Czech Republic 


\section{SIGNIFICANT WORKS ON DYNAMIC BANKRUPTCY PREDICTION}

The first to describe relationship between insolvency and ratio indicators was W. H. Beaver (1966). His research was later evolved by I.E. Altman (1968, p. 193) whose models are among the most used for bankruptcy prediction. In his research, Altman used discriminant analysis which consequently, along with logistic regression, became widely used tool for bankruptcy modelling.

The idea of both methods is to classify companies as heathy and in danger of bankruptcy. As opposed to this view, survival analysis models time until bankruptcy thus all companies are considered to be in danger of bankruptcy. Thus, the question of interest is when will this bankruptcy occur rather than whether it will occur. Results of such models therefore significantly differ from more traditional approach.

Table 1 offers overview of works of authors who used survival analysis to model bankruptcy probability.

Table 1. Most influential bankruptcy prediction works based on survival analysis

\begin{tabular}{|l|l|c|l|l|l|}
\hline \multicolumn{1}{|c|}{ Author } & $\begin{array}{c}\text { Country of } \\
\text { interest }\end{array}$ & $\begin{array}{c}\text { Publication } \\
\text { year }\end{array}$ & $\begin{array}{c}\text { Sample size / } \\
\text { out of which } \\
\text { bankrupted }\end{array}$ & \multicolumn{1}{|c|}{ Method } & \multicolumn{1}{|c|}{ Focus } \\
\hline Lane et al. & Not available & 1986 & $464 / 130$ & Proportional Cox & Banks \\
\hline Laitinen a Luoma & Finland & 1991 & $72 / 36$ & Proportional Cox & General \\
\hline José Pereira & Not available & 1994 & $27 / 11$ & $\begin{array}{l}\text { Collet and } \\
\text { parametrical Cox }\end{array}$ & Textile companies \\
\hline Shumway & USA & 1999 & $33621 / 291$ & $\begin{array}{l}\text { Hazard model of } \\
\text { own design }\end{array}$ & General \\
\hline Chava a Jarrow & USA & 2004 & $\begin{array}{l}\text { Most quoted } \\
\text { companies /1461 }\end{array}$ & $\begin{array}{l}\text { Discrete logistic } \\
\text { hazard model }\end{array}$ & Industry \\
\hline Kadri Männasoo & Estonia & 2007 & Not available & $\begin{array}{l}\text { Log-log hazard } \\
\text { function, i.e. } \\
\text { = Discrete } \\
\text { proportional } \\
\text { hazard model }\end{array}$ & $\begin{array}{l}\text { General, limited } \\
\text { to non-financial } \\
\text { companies older } \\
\text { than 3 years }\end{array}$ \\
\hline Gepp a Kumar & Not available & 2015 & $189 / 72$ & $\begin{array}{l}\text { Semi- } \\
\text { parametrical Cox }\end{array}$ & $\begin{array}{l}\text { Manufacture and } \\
\text { sales }\end{array}$ \\
\hline Taylor a Svec & USA & 2016 & $8664 / 546$ & $\begin{array}{l}\text { Accelerated } \\
\text { Failure Time }\end{array}$ & $\begin{array}{l}\text { General, non- } \\
\text { financial and no real } \\
\text { estate companies }\end{array}$ \\
\hline
\end{tabular}

Source: Own processing

Lane et al. (1986, pp. 511-531), Laitinen and Luoma (1991, pp. 673-678), José Pereira (2014) and Shumway (1999) were the first authors to use survival analysis in bankruptcy analysis. Shumway showed that dynamic models can have better results than static methods and survival analysis became not so scarce alternative to logistic regression and discriminant analysis. The most influential authors to use it since were Kadri Männasoo (2007) and Chava and Jarrow (2004). Lately, survival analysis in bankruptcy prediction was employed in particular by Ming-Chang Lee (2014, pp. 103-119), Gepp and Kumar (2015, pp. 369-404) and Taylor and Svec (2015).

The first author to have used survival analysis for bankruptcy prediction was Lane (1986, pp. 511-531). Data from 130 banks gone bankrupt between years 1978 and 1984 were used. Lane's results suggest that prediction abilities of Cox model are equal to those of discriminant analysis. 
Laitinen and Luoma (1991, pp. 673-678) applied survival analysis on sample of 36 bankrupt companies which were paired with 36 comparable heathy companies. Results were compared to logistic regression and discriminant analysis; survival analysis evinced slightly worse prediction abilities.

Pereira (2014) used Collet methodology and parametric Cox model on 11 bankrupt companies and 16 comparable heathy companies, all of which operating in textile sector. It is interesting that only 3 determinants out of 28 widely used determinants for insolvency prediction were proven to be significant showing just how much can inclusion of time change our view on bankruptcy.

Shumway (1999) offers further arguments for use of dynamic methods; closer fit to reality being the most prominent one. It is worth noticing that Shumway, in accordance with Pereira's findings, rejects statistical significance of variety of widely used bankruptcy indicators, including those suggested by Altman. In order to further support his statements, prediction model created in this paper was showed to have same or better results than Altman's model. Shumway renew his focus on survival analysis in his work with Bharath (2008, pp. 1339-1369) were his previous findings were confirmed. Chava and Jarrow (2004) verified Shumway's findings on exceptional sample size comprising monthly data from all American quoted companies.

Männasoo (2007) states that approaches based purely on data such as neural networks can outperform survival analysis in prediction power but admits that they lack additional information such as hazard function. Thus, Männasoo argues that survival analysis is more suitable for bankruptcy process explanation than other methods. Similar comparison was carried out in a paper by Gepp and Kumar (2015, pp. 369-404). Prediction abilities of semi-parametric Cox, non-parametric classification and regression trees and more traditional methods were compared. They conclude that both Cox and classification and regression trees draw level to more traditional methods and in accordance with Männasoo argue that the main advantage of survival analysis consists in additional information provided by survival analysis and time inclusion.

The only authors to use Accelerated Failure Time model were Taylor and Svec (2016). They argue that their model outperforms models created by both Shumway and Altman.

\section{SURVIVAL ANALYSIS STRENGTH AND WEAKNESSES}

In the middle of the first page of the paper, write the title. Use font Times New Roman Bold $14 \mathrm{pt}$, capital letters. Authors' names (bold) should be written in Times New Roman 12pt, in the middle of the page. Institutions' names, addresses and e-mail addresses in the footnote should be typed in Times New Roman 10 pt. An abstract with key words follows after the title and author's name written in Times New Roman bold and italic 12 pt.

To conclude their findings, main advantages of survival analysis are:

- Reality: Correspondence to reality as all companies will eventually bankrupt, bankruptcy is a function of time.

- Robustness: Ability to comprise information varying in time; therefore, it makes use of more data in order to create more robust estimates and in addition, there is no bias caused by choosing only one year to be considered by the model. (Shumway, 1999)

- Relaxed assumptions: Absence of multi-dimensional normality assumption, which is often violated, as opposed to e. g. discriminant analysis (Laitinen and Luoma, 1991, pp. 
673-678) and also absence of assumption requiring that the hidden process leading to bankruptcy does not change in time, as opposed to logistic regression. (Blossfeld, 2016)

- Additional information: Prediction of bankruptcy time, not only bankruptcy probability

Absence of division of companies into two populations (bankrupt and non-bankrupt), all companies are considered to be in danger of bankruptcy and thus belong to one population, only their bankruptcy probability differs (Keasey, 1990, pp. 85-94).

In our opinion, although survival analysis might not be more effective at prediction than other methods, it still is more than suitable for bankruptcy process description because of its dynamic approach being much closer to reality than more static classification approaches. Thus, its findings may be more reliable in uncovering bankruptcy process than traditional methods and may offer new insight. While aforementioned authors focused on prediction model creation, the aim of this paper is rather on uncovering hidden reasons for bankruptcy since we think that the potential of survival analysis has not been fully fulfilled in this area yet.

\section{METHODOLOGY}

Time modelled can be expressed as both hazard function and survival function. Several approaches to survival analysis can be employed, many of them are based on regression and thus suitable for predictions (Gepp and Kumar, 2015, pp. 369-404)). Often used model is Cox semi parametric model, Cox full parametric model and fully parametric Accelerated Failure Time model.

May X be time prior to an event, i.e. non-negative continuous and discrete quantify. In order to describe this quantity, survival function, hazard function, event density and cumulative hazard function are being used. (Moore, 2016)

If at least one of these characteristics is known, rest can be calculated. Other characteristics used include mean, average, standard deviation and quantiles.

Survival function models probability of company surviving given time if it did not bankrupt before this time. It is defined as (1):

$$
S(t)=P(T>t)
$$

I.e., it is probability that survival time will be higher than $\mathrm{x}$. The lifetime distribution function, conventionally denoted $F$, is defined as the complement of the survival function,

$$
S(t)=1-F(t)=1-P(T \leq t)
$$

Survival function can also be expressed as event density integral. Event density $f(t)$ is the rate of bankruptcy events per unit time.

$$
S(t)=\int_{x}^{\infty} f(t) d t
$$


If time is measured in discrete units as in the case of accounting data, survival function is modified to form number 4 :

$$
S(t)=\sum_{t_{j}<t} p\left(t_{j}\right)
$$

where $j=1,2, \ldots$ with probability function $p(t)=P\left(T=t_{j}\right)$ and where $t_{1}<t_{2}<\ldots<t_{n}$.

Hazard function $h(t)$ calculates probability that company will go bankrupt at time $t$ given that it had survived until time $t$. It is defined as non-negative function:

$$
h(t)=\lim _{\Delta t \rightarrow \infty} \frac{P[t \leq Y<t+\Delta t \mid T \geq t]}{\Delta t}
$$

Should time be measured in discrete units, hazard function can be modified to:

$$
h(t)=P\left(T=t_{j} \mid T \geq t_{j}\right)=\frac{p\left(t_{j}\right)}{S\left(t_{j-1}\right)}, \text { where } \mathrm{j}=1,2, \ldots \text { and } S\left(x t_{0}\right)=1 .
$$

Thus, hazard function can be defined through survival function modification:

$$
h(t)=1-S\left(t_{j}\right) / S\left(t_{j-1}\right)
$$

Cox model is one of proportional hazard models. Hazard function for company I can be expressed as:

$$
h\left(t, x_{i}\right)=h_{0}(t) \exp \left(x_{i 1} \beta_{1}+x_{i 2} \beta_{2}+\cdots+x_{i p} \beta_{p}\right)=h_{0}(t) \exp \left(x_{i}^{\prime} \beta\right)
$$

where $x_{i}$ are independent regressors for company $\mathrm{i}, \mathrm{p}$ is number of regressors, $\beta$ denotes regressors coefficients and $h_{0}(t)$ is baseline hazard function common for all companies.

Influence of independent variable on insolvency risk can be expressed through regression coefficients $\beta_{k}, k \in(1, \ldots, p)$, which denote change of risk connected to change of value of independent variable $k$. (Blower, 2004)

Partial likelihood method is used to coefficient estimates. Partial function is independent on baseline hazard $h_{0}(t)$, it depends on regression coefficients $\beta$, therefore:

$$
L(\beta)=\prod_{Y_{i} \text { not censored }} \frac{e^{X_{i} \beta}}{\sum_{Y_{j} \geq Y_{i}} e^{X_{j} \beta}}
$$

Regression coefficients estimates $\widehat{\beta}=\left(\hat{\beta}_{1}, \ldots, \hat{\beta}_{p}\right)$ can be connected to model results interpretation, in other words to hazard ratio. Hazard ratio estimate, $\widehat{H} R$, for subject $i$ and $j$ can be obtained $\hat{\beta}$ by substituting into following relationship:

$$
\widehat{H} R=\exp \left(\left(x_{i}-x_{j}\right)^{\prime} \hat{\beta}\right)
$$

Cox model in its original form assumes that values of regressors do not change in time. If varying data for each year are available (as in the case of accounting data), it is necessary to use generalization of Cox model, Cox model with time dependent variables. Such model assumes risk function for subject $i$ with vector of independent variables $x_{i}(t)$ to be: 


$$
h\left(t, x_{i}(t)\right)=h_{0}(t) \exp \left(x_{i 1}(t) \beta_{1}+\cdots+x_{i p}(t) \beta_{P}=h_{0}(t) \exp \left(x_{i}^{\prime}(t) \beta\right)\right.
$$

where $x_{i k}(t)$ are independent regressors for company $i$ in time $k, p$ is number of regressors, $\beta$ denotes regressors coefficients and $h_{0}(t)$ is baseline hazard function common for all companies. (Blower, 2004)

Proportional hazards model input usually contains one record for each company together with censorship indicator, but it can be reformulated as computer process where with growing time we observe new events for each company, thus for each company we have multiple observations. (Andersen and Gill, 1982)

Multiple companies are very likely to go bankrupt at once since we have discrete observations, therefore Breslow modification of maximum likelihood function will be used. (Grambsch, 2016)

In order to compare models among each other, Akaike information criterion will be used. In survival analysis context, this criterion is also used for variable selection. (Moore, 2016)

$$
A I C=2 * \text { number of estimated parameters }-2 \ln (L)
$$

Cox model assumes proportional hazards. In order to test this assumption, ZPH test with standardized Schoenfeld residues is used. (Grambsch, 2016)

\section{BANKRUPTCY DETERMINANTS}

Our sample consists of 52931 active Czech companies and 10752 Czech companies in different states of insolvency process. Data were download from Amadeus database. For each company, records from one to ten years and different financial statement information are available.

When examining bankruptcy process, determinant selection is very important, especially since based on literature review, survival analysis tends to favour different discriminants than static methods like logistic regression and discriminant analysis.

Table 2 presents determinants which will be considered in this paper. Changes between periods are computed as follows:

$$
\Delta \text { balance sheet entry }=\frac{\text { present value - last year value }}{\text { last year value }}
$$

With exception of indicators of changes between periods, table 2 presents mostly static view on bankruptcy determinants. However, main advantage of survival analysis consists in accounting for time, therefore it would be interesting to see changes of bankruptcy determinants few years before bankruptcy event.

Focusing on movements of above-mentioned determinants in years before bankruptcy, it turns out that total assets and equity ratio remain relatively stable through years even for companies nearing their bankruptcy with larger drop 3 years before bankruptcy event.

As opposed to this behavior, sales show high sensitivity to upcoming bankruptcy with steep drop each year. Decrease in sales and total assets ratio seems to be much more gradient than 
sales and equity ratio which drop quickly to zero. This is probably caused by simultaneous occurrence of low equity and low sales cancelling each other out.

Out of return ratios considered, upcoming bankruptcy had smallest effect on return on equity. This is caused by negative equity as a result of negative profit; therefore, we divide two negative values and get very positive outcome. For this reason, in our opinion, return on equity is not suitable for bankruptcy prediction modeling.

The last group of indicators considered are ratios based on current assets. These indicators remain relatively stable through observed period for non-bankrupt companies but slowly and steadily decrease for companies nearing bankruptcy.

Therefore, it is obvious that values of determinants considered vary drastically between non-bankrupt and bankrupt companies. In addition, we can observe change in values when bankruptcy is nearing, not only in the last year or year before bankruptcy as accounted by method logistic regression and discriminant analysis which make use only of one year.

Table 2. Considered bankruptcy determinants and their characteristics

\begin{tabular}{|c|c|c|c|}
\hline Determinant & Mean & $\begin{array}{l}\text { Standard } \\
\text { deviation }\end{array}$ & Employed in papers \\
\hline $\begin{array}{l}\text { Current assets and short-term liabilities } \\
\text { ratio }\end{array}$ & 1.801 & 2.51 & $\begin{array}{l}\text { Zmijewsky (1984), Pereira (2014), } \\
\text { Beaver (1966) }\end{array}$ \\
\hline Working capital and total assets ratio & 0.207 & 0.181 & $\begin{array}{l}\text { Altman (1968), Shumway (1990), } \\
\text { Beaver (1966), Taylor (2016) }\end{array}$ \\
\hline Working capital and total liabilities ratio & 0.364 & 0.839 & Pereira (2014) \\
\hline Total assets and total liabilities ratio & 1.871 & 1.838 & Beaver (1966), Taylor (2016) \\
\hline Equity and total assets ratio & 0.384 & 0.159 & $\begin{array}{l}\text { Quick test (Kralicek), Laitinen a } \\
\text { Luoma (1991) }\end{array}$ \\
\hline Sales and total assets ratio & 1.450 & 1.793 & $\begin{array}{l}\text { Altman (1968), Index bonity, Taffler, } \\
\text { Zmijewsky (1984), Shumway (1990), } \\
\text { Ming-Chang Lee (2014), Taylor } \\
(2016)\end{array}$ \\
\hline Return on short term liabilities & 0.103 & 0.092 & Taffler (2016) \\
\hline Return on total assets & 0.037 & 0.009 & $\begin{array}{l}\text { Altman (1968), Index bonity, Quick } \\
\text { test (Kralicek), Beaver (1966), } \\
\text { Shumway (1990) }\end{array}$ \\
\hline Return on equity & 0.151 & 0.068 & Taylor (2016) \\
\hline Sales and equity ratio & 2.181 & 12.044 & Ming-Chang Lee (2014) \\
\hline Total assets change between periods & 0.007 & 0.045 & Gepp a Kumar (2015) \\
\hline Cash Flow & 0.031 & 0.476 & Gepp a Kumar (2015) \\
\hline Tax change between periods & -0.10 & 1.040 & Gepp a Kumar (2015) \\
\hline Sales change between periods & -0.002 & 0.077 & Gepp a Kumar (2015) \\
\hline Equity change between periods & 0.058 & 0.060 & Gepp a Kumar (2015) \\
\hline $\begin{array}{l}\text { Short term liabilities change between } \\
\text { periods }\end{array}$ & -0.035 & 0.167 & Gepp a Kumar (2015) \\
\hline Current assets change between periods & 0.007 & 0.103 & Gepp a Kumar (2015) \\
\hline Profit change between periods & -0.349 & 1.037 & Gepp a Kumar (2015) \\
\hline Boolean indicator of positive equity & 0.793 & 0.164 & None \\
\hline Boolean indicator of positive profit & 0.604 & 0.239 & None \\
\hline $\begin{array}{l}\text { Boolean indicator of drop in total assets } \\
\text { higher than } 20 \%\end{array}$ & 0.141 & 0.121 & None \\
\hline
\end{tabular}

Source: own processing 


\section{STATISTICAL MODELING}

The correct specification of determinants is of the utmost importance for any prediction model. First, Akaike criterion as a cross validation approximation suitable for survival analysis will be employed for automatic variable pre-selection. Second, recursive variable selection based on significance and stability under different configurations will be applied.

Determinants which prove to be relevant in previous two steps will be subjected to kernel smoothing through natural cubic spline. This method allows us to uncover nonlinearity in determinant's effect on bankruptcy probability and subsequently include such modification that would work in linear settings of survival analysis.

It seems that working capital ratios as a group have lower strength than profitability ratios, on the other hand, sales ratios seem to be very closely connected to bankruptcy probability. It is interesting to note that under all configurations, the most influential ratio was always created using total assets. Thus, if an analyst was to choose only one ratio as a company health indicator, it should probably contain information about total assets. Significant determinants will be examined more closely through kernel smoothing.

Kernel smoothing through natural cubic splines helps in uncovering possible reasons for statistical insignificance in linear models by inclusion of knots and higher order polynomials while still not being too prone to overfitting thanks to linear constraints imposed on its parameters.

Figure 1 shows that the effect of change in sales is linear, i.e. twice as high growth in sales lowers the risk twice as much. Therefore, decrease in risk is very steady and bigger difference can be seen only at more extreme values where it seems that truly high increase in sales decreases more than proportionally risk of bankruptcy. However, the frequency of values at these extreme changes is not high enough to support this claim, i.e. confidence intervals are too wide.

We can see that change in equity effect is not monotonic; risk grows with high growth in equity in between periods. This is caused by calculation method when decrease in equity size from negative to even more negative value leads to very positive value of this indicator. That is the reason why determinants computed from two negative values like for example widely used return on equity (ROE) need to be used only in interaction with binary variable of positive equity.

Change in total assets shows exactly opposite behaviour from change in sales. Steep decrease in total assets from previous period has severe consequences on bankruptcy risk while moderate decrease lower than $20 \%$ or increase in assets have almost no effect. Thus, we might conclude that while sales might fluctuate naturally, severe decrease in total assets happens only when company is in serious distress. In addition, while increase in sales lowers the probability of bankruptcy, increase in total assets lacks this effect. Since total assets value seems to have only two main outcomes; negative when decrease is higher than $20 \%$ and neutral otherwise, it seems reasonable to create Boolean variable indicating whether between periods decrease in total assets was higher than $20 \%$.

Sales and total assets ratio influences bankruptcy risk only at very low values when. As soon as sales increase, further growth seems to have no effect on bankruptcy probability. However, this stands only as long as total assets are twice as big as sales because after this limit, number of observations is too scarce. Sales and equity ratio is not statistically significant. 

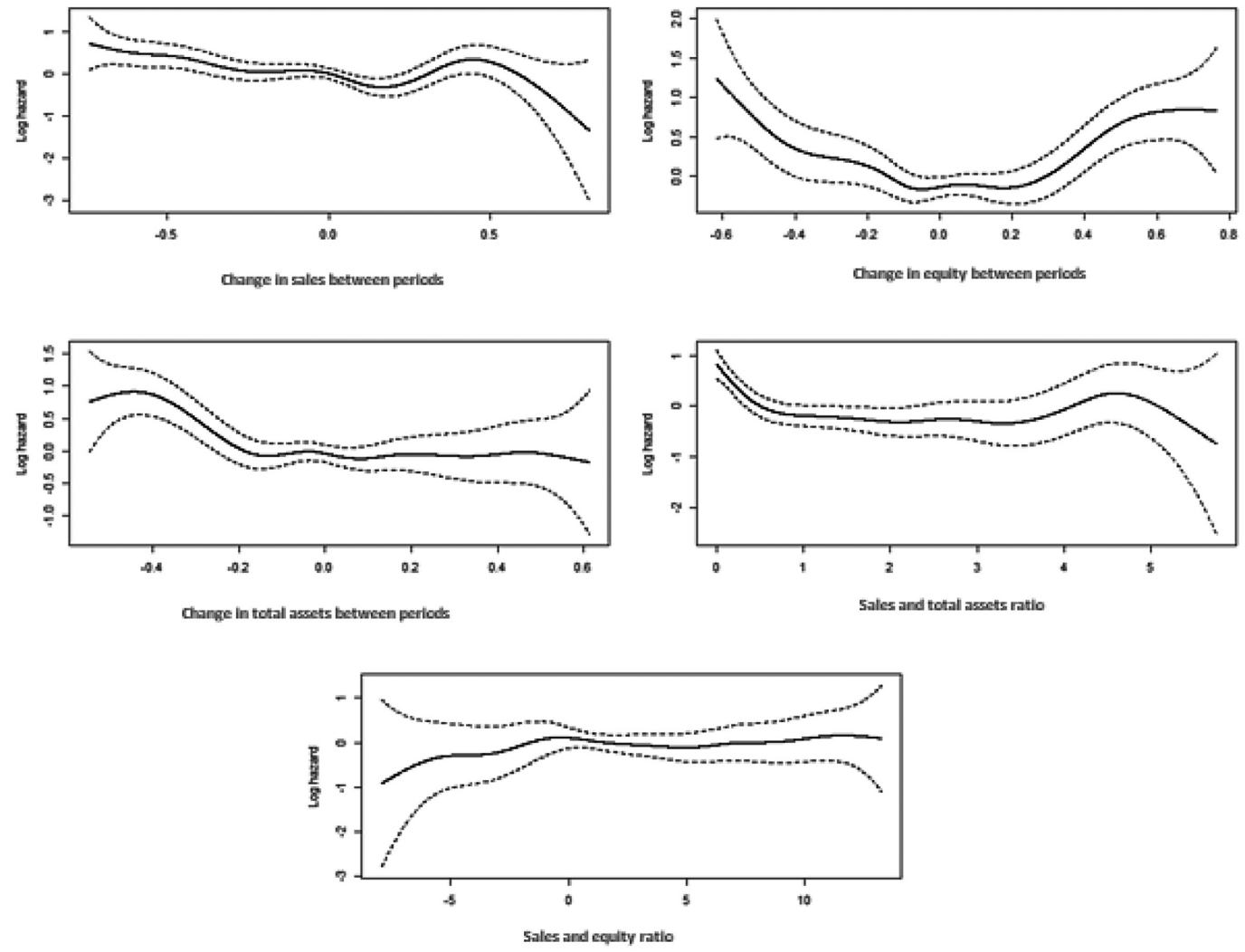

Figure 1. Influence of chosen determinants on bankruptcy risk

Source: Own processing
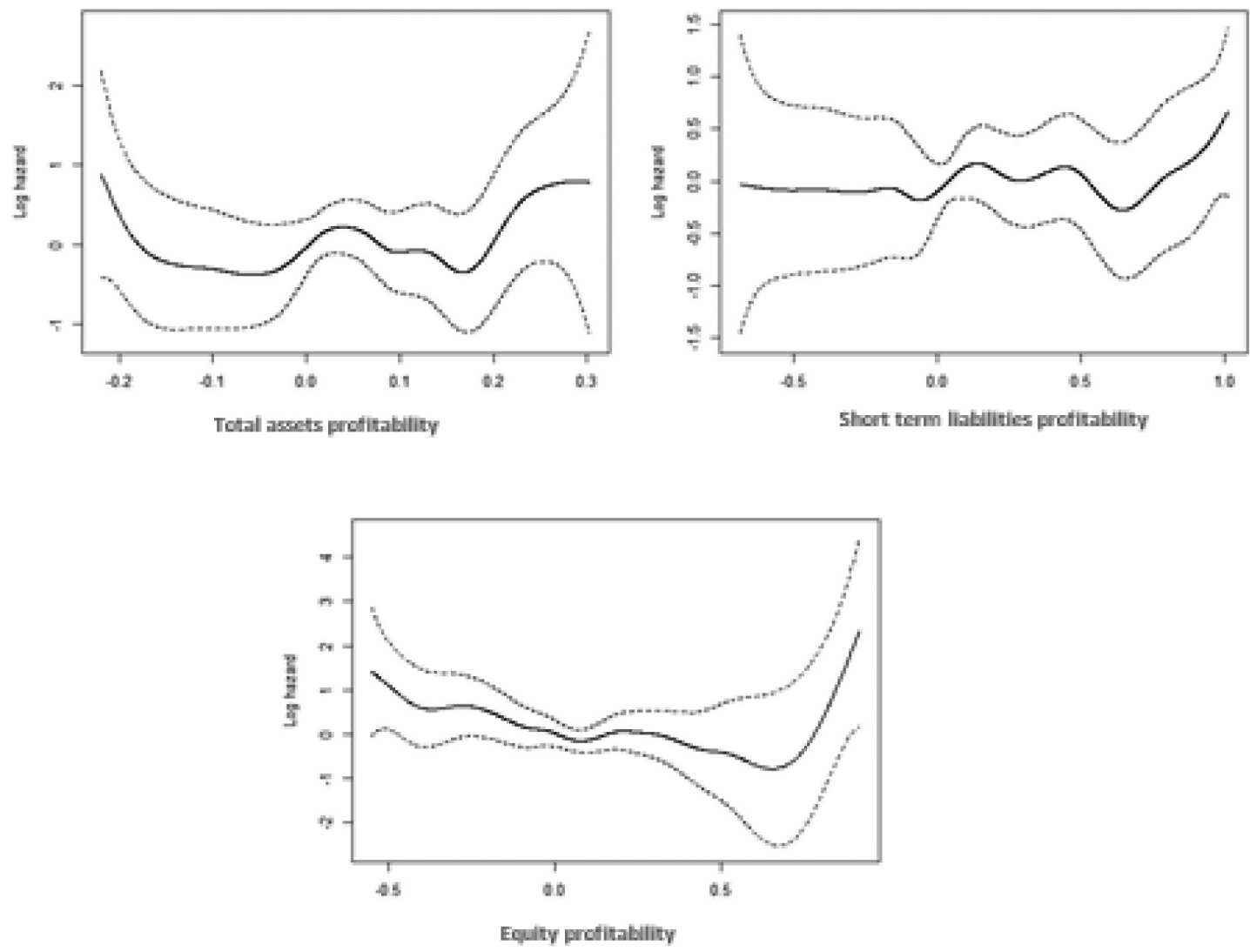

Figure 2. Effect of profitability ratios on bankruptcy risk

Source: Own processing 
Profitability is part of vast majority of bankruptcy models, see table 2, therefore it is surprising that profitability determinants have such poor properties to be part of statistical models. Monotonic decreasing line is to be expected but the empirical line is very uneven and ambivalent with wide confidence intervals. In the light of these findings, binary indicators of profit or loss seem to be a suitable alternative.

Table 3. Optimal survival model specification

\begin{tabular}{|l|c|c|c|c|}
\hline \multicolumn{1}{|c|}{ Variable } & Coefficient & $\begin{array}{c}\text { Exp } \\
\text { (coefficient) }\end{array}$ & $\begin{array}{c}\text { SE } \\
\text { (coefficient) }\end{array}$ & P-value \\
\hline Sales and total assets ratio & -0.273 & 0.761 & 0.041 & 0 \\
\hline Change in equity between periods & 0.766 & 2.152 & 0.353 & 0.030 \\
\hline Binary indicator of positive equity & -0.502 & 0.605 & 0.117 & 0 \\
\hline $\begin{array}{l}\text { Binary indicator of drop in total assets } \\
\text { more than 20 \% }\end{array}$ & -0.674 & 0.510 & 0.117 & 0 \\
\hline Change in sales between periods & -0.573 & 0.564 & 0.173 & 0.001 \\
\hline Binary indicator of positive profit & -0.443 & 0.641 & 0.106 & 0 \\
\hline $\begin{array}{l}\text { Interaction of binary equity indicator } \\
\text { and change in equity }\end{array}$ & -0.901 & 0.406 & 0.471 & 0.056 \\
\hline
\end{tabular}

Source: own processing

Table 4 aims to interpret these values in economic terms. It is interesting that binary variable of drop in total assets higher than $20 \%$ is so influential, especially compared to binary variable of positive profit where the effect seems rather small.

Table 4. Coefficient interpretation in economic terms

\begin{tabular}{|l|l|l|l|}
\hline \multicolumn{1}{|c|}{ Variable } & \multicolumn{1}{|c|}{ Applied at } & $\begin{array}{c}\text { Change in value of } \\
\text { variable }\end{array}$ & $\begin{array}{c}\text { Changes insolvency } \\
\text { risk by }\end{array}$ \\
\hline Sales and total assets ratio & All & Decrease of $50 \%$ & Increase of $25 \%$ \\
\hline $\begin{array}{l}\text { Change in equity in } \\
\text { between periods }\end{array}$ & Positive values & Decrease of $50 \%$ & Increase of $56 \%$ \\
\cline { 2 - 4 } $\begin{array}{l}\text { Change in total assets in } \\
\text { between periods }\end{array}$ & All & Decrease of $50 \%$ & Increase of $47 \%$ \\
\hline $\begin{array}{l}\text { Change in sales between } \\
\text { periods }\end{array}$ & All & $\begin{array}{l}\text { Decrease higher than } \\
20 \%\end{array}$ & Increase of $96 \%$ \\
\hline $\begin{array}{l}\text { Binary variable of positive } \\
\text { profit }\end{array}$ & All & Decrease of $50 \%$ & Increase of $25 \%$ \\
\hline
\end{tabular}

Source: own processing

Survival analysis model presented can uncover $65 \%$ of companies about to go bankrupt next year. This result is satisfactory since most bankruptcy models have similar prediction power and the strength of survival analysis is rather more realistic view on insolvency than in prediction power.

\section{CONCLUSION}

The aim of this paper was examination of bankruptcy determinants from the time dependent survival analysis point of view.

Percentual changes from previous period have proven to be very powerful alternative to ratio indexes, out of which changes in equity from previous year, change in sales and change in assets seem to most closely connected to bankruptcy risk. 
In addition, change in total assets acts very differently than change in sales. More significant decrease in total assets has severe influence on bankruptcy risk while moderate decrease lower than $20 \%$ or even increase seem to have none or very small impact. On the other hand, effect of sales is lineal; increase in sales lowers the bankruptcy risk, decrease in sales causes a steady growth in said risk. Therefore, it seems that while total assets might decrease naturally up to $20 \%$ without higher probability bankruptcy, any decrease in sales does increase bankruptcy risk.

In comparison to truly high influence based on change in between periods, one may be surprised at insignificance of profitability and working capital indexes. Profitability indexes seem to be quite unstable and unresponsive to nearing bankruptcy event, this behaviour is probably caused by simultaneous decrease in profit and assets or sales of distressed companies cancelling each other out. Working capital indexes might still be influential at short term prediction while our prediction horizon was in years. Out of most commonly used determinants, only one was able to compete with percentual changes from previous period and that was sales and total assets ratio.

The true benefit of this paper lies in empirical broadening of knowledge we have regarding processes in companies nearing their bankruptcy. Survival analysis is a method which sees bankruptcy as a dynamic process happening in time, therefore the determinants of bankruptcy which were marked by this method as significant could be much closer to real reasons or symptoms of bankruptcy than determinants commonly used. Therefore, when assessing company's bankruptcy risk, one should focus on changes from previous year, especially decrease in equity, sales and total assets higher than $20 \%$ rather than looking at profitability and working capital ratios.

\section{ACKNOWLEDGMENT}

Support of the Masaryk University grand No. MUNI/A/1092/2017 is gratefully acknowledged.

\section{REFERENCES}

Altman, E. (1968). The Prediction of Corporate Bankruptcy: A Discriminant Analysis. The Journal of Finance, 23(1), pp.193.

Beaver, W. (1966). Financial ratios as predictors of business failure.

Bharath, S. \& Shumway, T. (2008). Forecasting Default with the Merton Distance to Default Model. Review of Financial Studies, 21(3), pp.1339-1369.

Blossfeld, H. (2016). Event History Analysis, Psychology Press.

Chava, S. \& Jarrow, R. (2001). Bankruptcy Prediction With Industry Effects, Market Versus Accounting Variables, And Reduced Form Credit Risk Models. SSRN Electronic Journal.

Gepp, A. \& Kumar, K. (2015). Predicting Financial Distress: A Comparison of Survival Analysis and Decision Tree Techniques. Procedia Computer Science, 54, pp.396-404.

Grambsch, P. \& Therneau T. (2016), Proportional hazards tests and diagnostics based on weighted residuals. Biometrika, 81 .

Keasey, K., McGuinness, P. \& Short, H. (1990). Multi logit approach to predicting corporate failure-Further analysis and the issue of signal consistency. Omega, 18(1), pp.85-94.

Lane, W., Looney, S. \& Wansley, J. (1986). An application of the cox proportional hazards model to bank failure. Journal of Banking \& Finance, 10(4), pp.511-531.

Lee, M. (2014). Business Bankruptcy Prediction Based on Survival Analysis Approach. International Journal of Computer Science and Information Technology, 6(2), pp.103-119. 
Luoma, M. (1991). Survival analysis as a tool for company failure prediction. Omega, 19(6), pp.673-678.

Männasoo, K. (2007). Determinants of firm sustainability in Estonia. [Tallinn]: Eesti Pank.

Moore, D. (2016). Applied survival analysis using $R$.

Pereira, J. (2014). Survival Analysis Employed in Predicting Corporate Failure: A Forecasting Model Proposal. International Business Research, 7(5).

Shumway, T. (1999). Forecasting Bankruptcy More Accurately: A Simple Hazard Model. SSRN Electronic Journal.

Taylor, William \& Svec J. (2016) Distress Risk: An Accelerated Failure Time Survival Analysis Approach.

Zmijewski, M. (1984). Methodological Issues Related to the Estimation of Financial Distress Prediction Models. Journal of Accounting Research, 22, p.59. 